Article

\title{
Development of a Composite from TPS-EVOH-SBR Reinforced with Coconut Fiber
}

\author{
Jonathan Meráz-Rivera ${ }^{1}$, Lidilia Cruz-Rivero ${ }^{1, * \mathbb{C}}$, María Leonor Méndez-Hernández ${ }^{1}$,

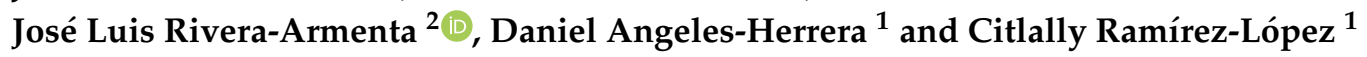 \\ 1 Tecnológico Nacional de México/Instituto Tecnológico Superior de Tantoyuca, División de \\ Posgrado e Investigación. Desv. Lindero Tametate S/N La Morita, Tantoyuca, Veracruz 92100, Mexico; \\ meraz.rivera.j.22@gmail.com (J.M.-R.); draleonormendez@gmail.com (M.L.M.-H.); \\ dangelesh0600@alumno.ipn.mx (D.A.-H.); citlallyrl@yahoo.com.mx (C.R.-L.) \\ 2 Tecnológico Nacional de México/Instituto Tecnológico de Ciudad Madero, Centro de investigación \\ en petroquímica. Prol bahia de Aldahir y Av de las Bahias, Parque de la Pequeña y Mediana Industria, \\ Altamira 89600, Mexico; jlriveraarmenta@itcm.edu.mx \\ * Correspondence: lilirivero@gmail.com; Tel.: +52-7891005673
}

Received: 14 August 2020; Accepted: 15 September 2020; Published: 23 September 2020

\begin{abstract}
The aim of this research is to obtain a composite made of coconut fiber, thermoplastic starch (TPS), ethylene vinyl alcohol (EVOH), and styrene-butadiene copolymer (SBR), achieving the most significant criteria/attribute determined by users. The tools used were quality function deployment (QFD) and the theory of inventive problem solving (TRIZ). The end result indicated that the quality requirement and most representative attribute for users is the toxicity of the material. Four mixtures were made with different percentages of coconut fiber, TPS-EVOH, and SBR, subjecting them to Fourier transform infrared spectroscopy (FTIR), dynamic mechanical analysis (DMA), and thermogravimetric analysis (TGA). The material obtained complies with the requirements of the Food and Drug Administration (FDA) regarding the nontoxicity of synthetic materials (EVOH and SB) to be used in contact with food (packaging and packaging). The spectra IR of the presence of monomers such as methacrylic acid, 2-hydroxyethyl acrylate, itaconic acid, among others, was not detected due to the humidity of the material. On the other hand, the DMA graphs showed that the mixtures achieved high storage modules (from 1500 to $3000 \mathrm{MPa}$ ) at temperatures from -90 to $-70{ }^{\circ} \mathrm{C}$, and the TGA thermogram showed that the last material to degrade was SBR at temperatures from 400 to $500{ }^{\circ} \mathrm{C}$.
\end{abstract}

Keywords: QFD; TRIZ; coconut fiber; TPS; EVOH

\section{Introduction}

The production of conventional plastics is causing great damage to the world. About $80 \%$ of the manufactured plastic accumulates as garbage in landfills and natural environments, presenting an increased risk [1]. According to the OECD [2,3] and European Bioplastics [4], the plastic production worldwide in 2015 was 407 million tons, while the production of bioplastics in 2018 was 2.11 million tons, that is, less than $1 \%$ of total production worldwide [5].

Due to an increase in the consumption of fossil fuels, the limitation of resources, fluctuations in prices, and the impact on the environment, a trend has emerged towards the use of biodegradable materials [6]. Therefore, the interest in the care of the environment and the replacement of conventional plastics is increasing.

With the world panorama of conventional plastics production, it is important to consider methodologies that contribute to the context of innovation, design, and manufacture of biodegradable 
materials. Nowadays, QFD and TRIZ are a set of techniques that contribute to innovative ideas by listening and attending to the voice of end-users. These methodologies allow producers to satisfy certain requirements, criteria, characteristics, and specific attributes that the end-users consider relevant or significant.

The combination of both methodologies (TRIZ and QFD) can generate enormous potential for innovation, ensure the prerequisites for a successful product, remove barriers to ideas, and extend the horizon of knowledge [7].

In previous works, QFD and the analytical hierarchy process (AHP) was used in the selection of a thermoplastic matrix mixed with a natural fiber for an automotive stabilizer bar. The authors realized that the most significant requirement for the bar design was high durability and reliability, and the best thermoplastic matrix to combine with hemp fiber was a thermoplastic polyurethane matrix (TPU-22.30\%) [8].

TRIZ is a methodology from which an ideal final result is obtained in the design and development of products, considering inventive parameters in a matrix of contradictions. In a study related to the design of a natural fiber metallic laminate, TRIZ was used to reduce the weight of the front hood of the car, considering three pairs of contradictions: (1) weight vs. reliability, (2) strength vs. machinability, and (3) strength vs. strength. The inventive principles that they used to solve each contradiction were (40) composite material, (3) local quality, and (37) thermal expansion, resulting in the weight of the hood being reduced from $30 \%$ to $80 \%$ when using natural fiber metallic laminate [9].

In a study for the functional optimization of Persian lime packaging, genetic algorithms and TRIZ were used. From the matrix of contradictions of this methodology, two aspects were considered for packaging: (1) quantity of substance vs. resistance, and (2) shape vs. volume of an object without movement, resulting in the principles of (10) preliminary action and (35) transformation of the physical and chemical states of an object. Applying Principles 10 and 35 ensured that the new design had economic savings, decreased environmental impact, and greater functionality [10].

Fourier transform infrared spectroscopy (FTIR) studies are a technique that is based on the interaction of electromagnetic radiation in the thermal infrared region; it measures different types of vibrations between atoms according to their atomic bonds and allows the distinction of the bands associated with functional groups of interest in the spectra generated [11-14]. In similar studies to the proposed work, FTIR has shown that coconut fiber has absorption peaks in its IR spectrum at 1741 and $1511 \mathrm{~cm}^{-1}$, corresponding to the conjugated stretch $\mathrm{C}=\mathrm{O}$ of hemicellulose aldehyde and ester, absorption at $1332 \mathrm{~cm}^{-1}$ of $\mathrm{C}-\mathrm{H}$ in the flat deformation of cellulose rings, bands in $1038 \mathrm{~cm}^{-1}$ of $\mathrm{C}-\mathrm{O}$ groups of hemicellulose, cellulose, and $\mathrm{C}-\mathrm{H}$ (lignin deformation), and stretch for the cellulose glucose ring structure at $897 \mathrm{~cm}^{-1}$ [15].

In another work related to coconut fiber, it was obtained in the IR spectrum absorption peaks assigned to polysaccharides at 3327.7 and $3320.9 \mathrm{~cm}^{-1}$, a very large and intense peak attributed to C-O bonds of alcohols related to the cellulose molecule at 1028.1 and $1023.9 \mathrm{~cm}^{-1}$, and a band representing the aliphatic group $\mathrm{CH}$ connected to the aromatic ring at 2890.9 and $2881.8 \mathrm{~cm}^{-1}$, which confirms the presence of lignin [16].

Other studies have observed peaks in the IR spectrum of coconut fiber at 3435 and $2930 \mathrm{~cm}^{-1}$ corresponding to cellulose, and absorption bands at 1734 and $1248 \mathrm{~cm}^{-1}$ of hemicellulose, with the remaining bands belonging to lignin $\left(1025,799,699\right.$, and $\left.675 \mathrm{~cm}^{-1}\right)$ [17].

Thermogravimetric analysis (TGA) is a technique used to investigate the decomposition process of materials, where the change in the mass of a polymer is measured as a function of temperature or time in a controlled atmosphere $[18,19]$. In a previous work about the role of major constituents of coconut fibers on the absorption of ionic dyes, plant fibers have been reported to have four stages of decomposition: in the first stage, water loss is generated, the second is hemicellulose, the third cellulose, and the fourth lignin [15], usually consisting of $60-80 \%$ cellulose, $10-24 \%$ hemicellulose, $3-12 \%$ lignin, and up to $5 \%$ pectin and water. In particular, coconut fiber concentrates between $40-45 \%$ 
cellulose, $24 \%$ hemicellulose, and $30-40 \%$ lignin. Hemicellulose begins its degradation process at around $180^{\circ} \mathrm{C}$, cellulose around $240^{\circ} \mathrm{C}$, and lignin at $280^{\circ} \mathrm{C}$ [15].

By FTIR analysis, coconut fiber was evaluated as reinforcement in PHB (polyhydroxybutyrate) as a polymer matrix. Thermogravimetric analysis showed that the presence of fiber in the PHB matrix improved the thermal stability of the composite. SEM analysis of the microstructure showed good interfacial adhesion between PHB and coconut fiber, especially when treated fiber was used. [20].

Dynamic mechanical analysis (DMA) is an effective tool to determine the morphology and viscoelastic properties of a polymer and/or compound materials related to primary relaxations and other parameters. This analysis is often associated with the "stiffness" of a material and determines how rigid or weak a sample is, obtaining as a result (parameters) the storage modulus ( $\left.E^{\prime}\right)$, the loss modulus $\left(E^{\prime \prime}\right)$, and the loss factor $(\tan \delta)$. This factor depends on temperature, providing information on the interfacial bond between the reinforced filler and the polymer matrix of the composite material [21,22]. For the purposes of this particular study, a dynamic mechanical analysis will be carried out with a DMA-Q800 TA-Instrument.

The aim of this research is to obtain a composite made of coconut fiber, thermoplastic starch (TPS), ethylene vinyl alcohol (EVOH), and styrene-butadiene copolymer (SBR), achieving the most significant criteria/attributes determined by users.

\section{Materials and Methods}

QFD and TRIZ methodologies are used to define the technical requirements of the users and the design parameters in the creation of a partially biodegradable material made of coconut fiber (FC), TPS-EVOH, and styrene-butadiene copolymer (SBR), on which to subsequently perform the FTIR, DMA, and TGA tests.

As the first stage of the investigation involves listening to the end-users, a survey was formulated and applied to professionals and specialists in the area of biodegradable or related materials in order to collect significant information regarding the characteristics that the partially biodegradable materials must have.

The collection of information obtained through the survey was then directed to the QFD and TRIZ methodologies to analyze and define the technical requirements and suitable design parameters, satisfying the corresponding need or criterion.

\subsection{Deployment of Quality Function (QFD)}

The QFD methodology consists of the elaboration and construction of a house of quality (HoQ), which shows, through a matrix, all the requirements of the valued customers (RC), as well as the functional requirements or technical characteristics of the products (CT).

The requirements of the clients, as evaluated by the HoQ in the investigation, were rugged, nontoxic, low cost, lightweight, good design, reliable, compliant, functional, fast degradation, nonpolluting, manufacturable, compliant with design standard, recyclable, and easy to purchase.

\subsection{Inventive Problem Solving Theory (TRIZ)}

TRIZ is a methodology proposed by Genrich Altshuller to solve inventive problems and, for more than 60 years of development, it has been used by many researchers and entrepreneurs to improve their goods, processes, and services, thanks to the effectiveness and efficiency that it provides. This methodology includes techniques and tools that can be used to logically develop creativity in the process of designing innovative products [23].

In the investigation, the matrix of contradictions of the TRIZ methodology was used, with the objective of locating inventive principles that will guide a solution to reach the quality requirements defined by the HoQ of the QFD methodology. 


\subsection{Preparation of the Mixture}

The materials used to obtain the composite mixture were coconut fiber, thermoplastic starch (TPS) with ethylene vinyl alcohol (EVOH) matrix, and styrene-butadiene copolymer (SBR). The Intelli-Torque Brabender PL2000 Rheometer equipment was used, establishing conditions at $100{ }^{\circ} \mathrm{C}$ for $20 \mathrm{~min}$, with a speed of $50 \mathrm{RPM}$, to perform the mixing of the materials. To obtain the compaction of the mixture, DAKE Press model $944225-1$ was used at pressing temperature $120^{\circ} \mathrm{C}$, pressure 5 , and 10 ton, with 2 min pressing.

The concentration of each sample is described below (see Table 1), where FC is coconut fiber, TPS-EVOH is thermoplastic starch with ethylene vinyl alcohol matrix, SBR is styrene-butadiene copolymer, and the numbers indicate the $\%$ of participation of the material.

Table 1. Proportions of the mixtures made.

\begin{tabular}{ccccccccc}
\hline \multirow{2}{*}{ Mix N } & \multicolumn{2}{c}{ Coconut Fiber } & \multicolumn{2}{c}{ TPS-EVOH } & \multicolumn{2}{c}{ (SBR) } & \multicolumn{2}{c}{ Total mix } \\
\cline { 2 - 9 } & $\mathbf{g}$ & $\mathbf{\%}$ & $\mathbf{g}$ & $\mathbf{\%}$ & $\mathbf{g}$ & $\mathbf{\%}$ & $\mathbf{g}$ & $\mathbf{\%}$ \\
\hline 1 & 5.0 & $11.11 \%$ & 25.0 & $55.56 \%$ & 15.0 & $33.33 \%$ & 45.0 & $100.0 \%$ \\
2 & 2.6 & $4.73 \%$ & 23.6 & $42.91 \%$ & 28.8 & $52.36 \%$ & 55.0 & $100.0 \%$ \\
3 & 5.0 & $9.09 \%$ & 22.5 & $40.91 \%$ & 27.5 & $50.00 \%$ & 55.0 & $100.0 \%$ \\
4 & 7.1 & $12.91 \%$ & 21.5 & $39.09 \%$ & 26.4 & $48.00 \%$ & 55.0 & $100.0 \%$ \\
\hline \multicolumn{3}{c}{ Source: authors. }
\end{tabular}

\subsection{Characterization of the Mixtures}

The obtained samples were characterized by three different teams to analyze their physical-chemical properties and, thus, determine if the quality requirements established by professionals and specialists are met since it is an important element considered for the study. The conditions of the equipment that was used for the characterization of the specimens are mentioned below.

\subsubsection{Infrared Spectroscopy (FTIR)}

The infrared spectroscopy technique was used to identify the functional groups of the samples in the Perkin Elmer Spectrum One equipment, using an attenuated total reflectance (ATR) accessory; the analysis conditions were 16 scans in the range of $4000-600 \mathrm{~cm}^{-1}$, with a resolution of $4 \mathrm{~cm}^{-1}$.

\subsubsection{Dynamic Mechanical Analysis (DMA)}

DMA-Q800 TA-Instrument equipment was used to carry out the dynamic mechanical analysis; the dimensions of the samples were $20.00 \times 10.34 \times 4.54 \mathrm{~mm}$ (length/width/thickness). The analysis was performed at a temperature range of -100 to $200{ }^{\circ} \mathrm{C}$, with a heating rate of $5^{\circ} \mathrm{C} / \mathrm{min}$ and a frequency of $1 \mathrm{~Hz}$.

\subsubsection{Thermogravimetric Analysis (TGA)}

Thermogravimetric analysis was carried out with the SDT (DSC-TGA) Q600 TA-Instrument using a $10 \pm 2 \mathrm{mg}$ sample in a platinum tray, with a nitrogen $(\mathrm{N})$ flow of $100 \mathrm{~mL} / \mathrm{min}$, a gradual ramp of $10^{\circ} \mathrm{C} / \mathrm{min}$, and a temperature range from 30 to $700^{\circ} \mathrm{C}$.

\section{Results}

\subsection{Quality Function Deployment (QFD)}

With the application of QFD, it was possible to identify the most significant attribute that end-users (surveyed) perceived as a priority in a material that is made up of partially biodegradable materials. 
To develop HoQ, it is necessary to collect the voice of customers, so before applying the QFD methodology, a survey was conducted on a target group. This group was made up of specialists and professionals in the area of biodegradable or related materials. The requirements evaluated in the survey were (Figure 1).

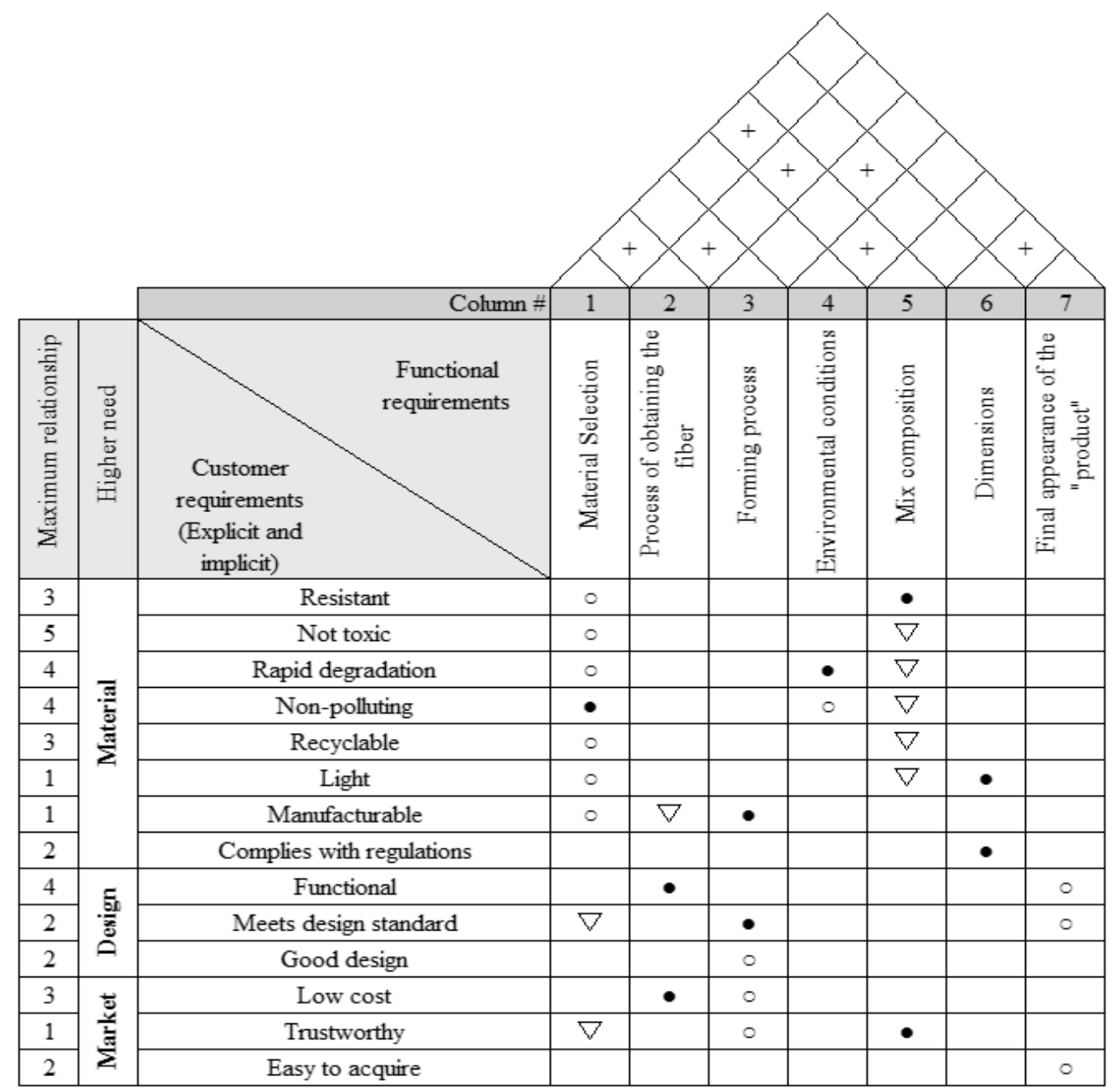

Figure 1. House of quality [24]. (Source: authors).

1. Resistant;

2. Nontoxic;

3. Low cost;

4. Lightweight;

5. Good design;

6. Reliable;

7. Normative;

8. Functional;

9. Rapid degradation;

10. Nonpolluting;

11. Manufacturable;

12. Recyclable;

13. Easy to purchase (acquire). 
Figure 1 shows the HoQ, where quality requirements are analyzed. These quality requirements are the requirements that the customer mentions as important.

The result of the analysis with QFD highlights the "nontoxic" quality requirement; that is, the clients expect that the proposed composition, based on TPS-EVOH-SBR and coconut fiber, is not toxic. Therefore, starting from this quality requirement, we proceeded to make the transition and translation to an improvement parameter in the TRIZ methodology.

The parameters and principles of the TRIZ methodology are aimed at improving and guiding an aspect, characteristic, or property of a product or service; in this case, it refers to nontoxicity, which will be considered as the parameter to be improved (A) according to TRIZ.

After carrying out an analysis and comparative search in relation to the translation of the quality requirement versus parameter, it was possible to establish that the client's "nontoxic" requirement can be verbalized to "harmful factors acting on the object", which is represented by Parameter 30 of the 39 parameters constituted in the TRIZ methodology (Figure 2).

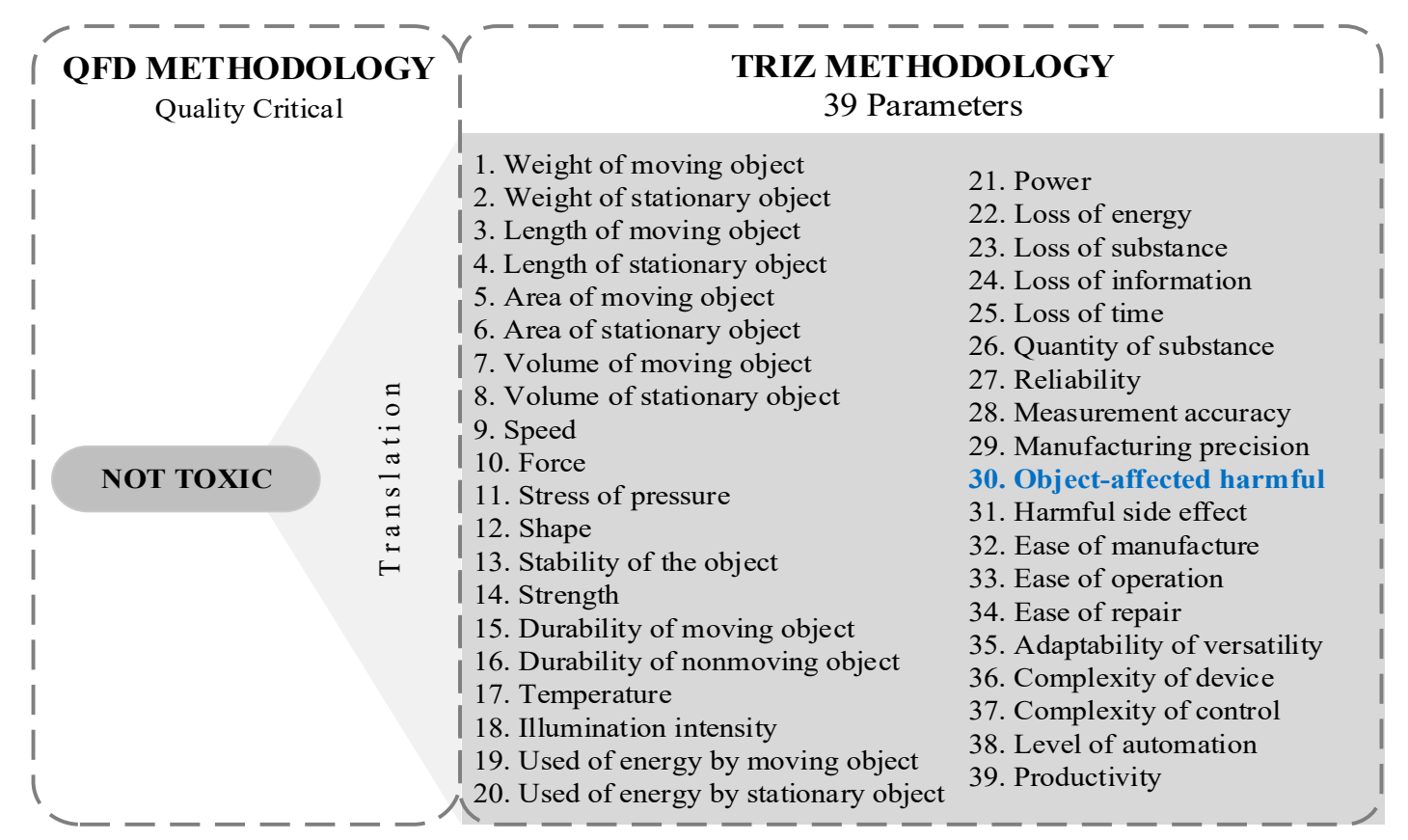

Figure 2. Translation of the quality requirement (QFD) to parameters (TRIZ). Source: authors.

The pairs in conflict are the parameters $(\mathrm{A}, \mathrm{B})$ that the target group has identified as the most outstanding characteristics that the composite should have, considering parameter (B) as a characteristic that could be affected when improving parameter (A); therefore, the resulting conflicting pairs based on Parameter 30 were

- Parameter 14: Strength or resistance,

- Parameter 16: Durability of the immobile object, and

- Parameter 26: Quantity of substance.

Based on the improvement parameter (A), the following conflicting pairs, represented in Table 2, were established. 
Table 2. Definition of parameter A and parameter B, according to the TRIZ methodology.

\begin{tabular}{|c|c|c|c|}
\hline $\begin{array}{c}\text { Quality } \\
\text { Requirement }\end{array}$ & $\begin{array}{l}\text { Parameter A } \rightarrow \text { Improvement } \\
\text { (TRIZ Parameter Translation) }\end{array}$ & $\begin{array}{l}\text { Parameter B } \rightarrow \\
\text { Gets Worse }\end{array}$ & $\begin{array}{l}\text { Inventive Principles } \\
\text { According to TRIZ } \\
\text { Methodology }\end{array}$ \\
\hline \multirow[t]{3}{*}{ Not toxic } & \multirow{3}{*}{ 30. Object-affected harmful } & 14. Strength or resistance & $\begin{array}{l}\text { 1. Segmentation. } \\
\text { 18. Mechanical vibrations. } \\
\text { 35. Change of parameters } \\
\text { (physical states). } \\
\text { 37. Thermal expansion. }\end{array}$ \\
\hline & & $\begin{array}{l}\text { 16. Durability of } \\
\text { nonmoving object. }\end{array}$ & $\begin{array}{l}\text { 1. Segmentation. } \\
\text { 17. Dimensional change. } \\
\text { 33. Homogeneity. } \\
\text { 40. Use composite materials. }\end{array}$ \\
\hline & & $\begin{array}{l}\text { 26. Quantity of } \\
\text { substance. }\end{array}$ & $\begin{array}{l}\text { 29. Pneumatics and } \\
\text { hydraulics. } \\
\text { 31. I use porous materials. } \\
\text { 33. Homogeneity. } \\
\text { 35. Change of parameters } \\
\text { (physical states). }\end{array}$ \\
\hline
\end{tabular}

Source: authors.

As shown in the inventive principles column of Table 2, there are inventive principles that are repeated in each of the pairs in conflict $(\mathrm{A}, \mathrm{B})$, which is a way of selecting the inventive principle to use and develop once parameter $B$ is established, considering that inventive principles are those that are repeated in the other pointed pairs in conflict (as long as several pairs in conflict have been defined). Therefore, the conflicting torque selected for this investigation was Parameter 30 vs. Parameter 14, with inventive Principles 1, 35, and 37.

The mentioned inventive principles were used in the following way to create the mixture of the partially biodegradable material:

- Principle 1: segmentation. It is presented based on the mentioned materials since the materials are arranged separately and mixed in different proportions.

- Principle 35: change of parameters (physical states). After preparing the first mixture of coconut fiber $(11.11 \%)$, TPS-EVOH (55.56\%), and SBR $(33.33 \%)$, it was observed that the homogeneity of the mixture was not as desired (see Figure 3); therefore, Principle 35 was applied to change the physical state of the coconut fiber. For this, the coconut fiber was ground in a conventional mill and sieved to obtain fiber microparticles and, thus, improve this factor.

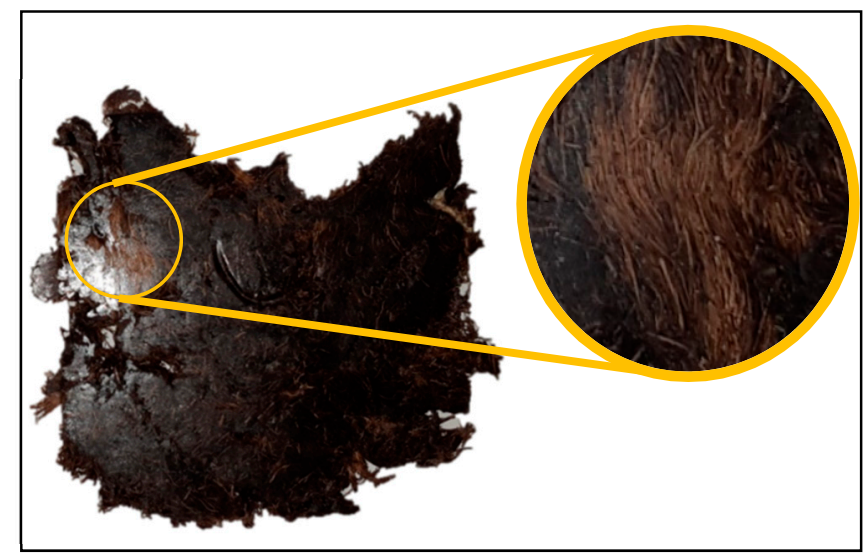

Figure 3. Coconut fiber crowding in the first mix. 
- Principle 37: thermal expansion. Preliminary mixtures were prepared under the principle of thermal expansion of the TRIZ methodology to observe the behavior and properties at different temperatures. In studies $[20,22,25]$, temperatures of $185,170,160$, and $150^{\circ} \mathrm{C}$ were used to make mixtures; for this study, temperatures of 100,150 , and $170{ }^{\circ} \mathrm{C}$ were used.

\subsection{Infrared Spectroscopy (FTIR)}

Figure $4 \mathrm{a}, \mathrm{b}$ shows the IR spectra for SBR, TPS-EVOH, and the four mixtures made from FC/TPS-EVOH/SBR (see Table 1) of 4000 and $600 \mathrm{~cm}^{-1}$. It is possible to identify some of the functional groups in the blends of the elastomers with TPS-EVOH and the mixtures. The SBR signals at 3000 and $3100 \mathrm{~cm}^{-1}$ are associated with unsaturated carbons; meanwhile, at 2900 and $2850 \mathrm{~cm}^{-1}$, the signals are related to the stretching of methyl and methylene groups. Moreover, the region of the aromatic ring is visible from 2000 to $1850 \mathrm{~cm}^{-1}$ [20].

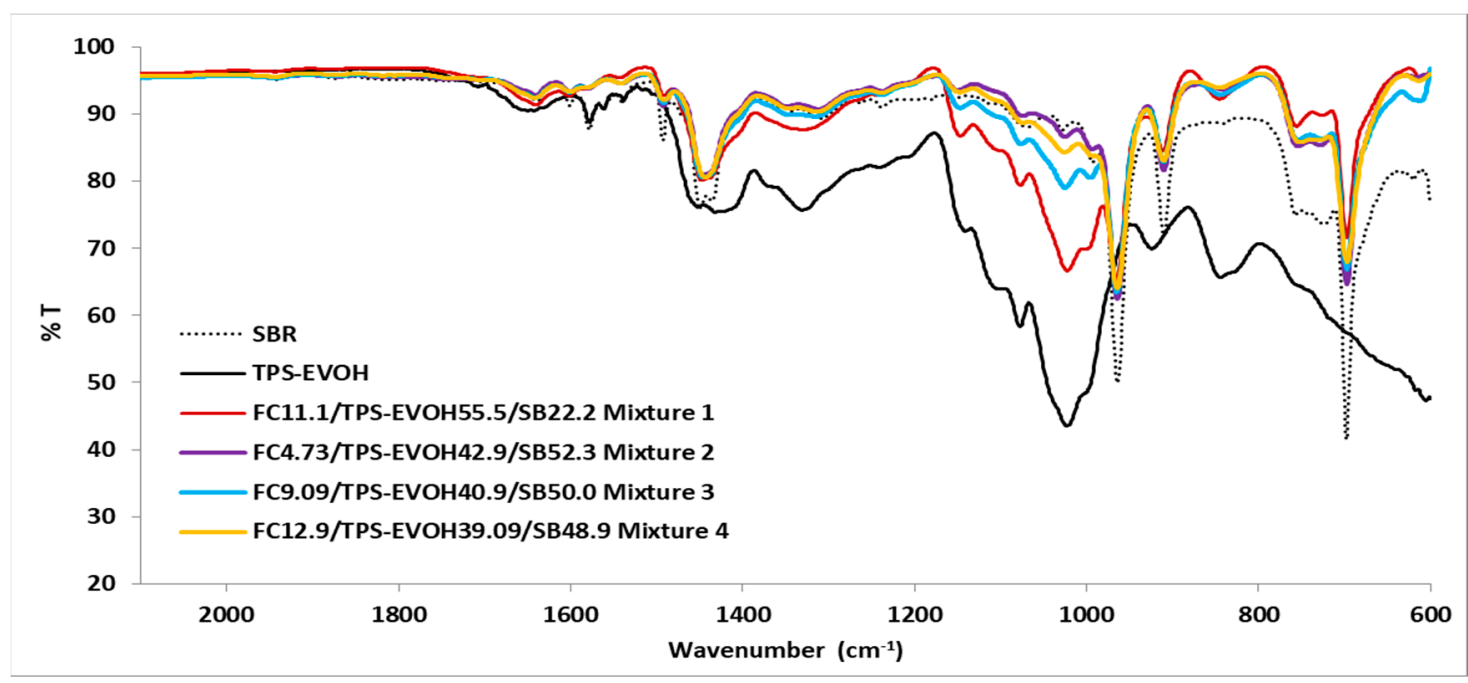

(a)

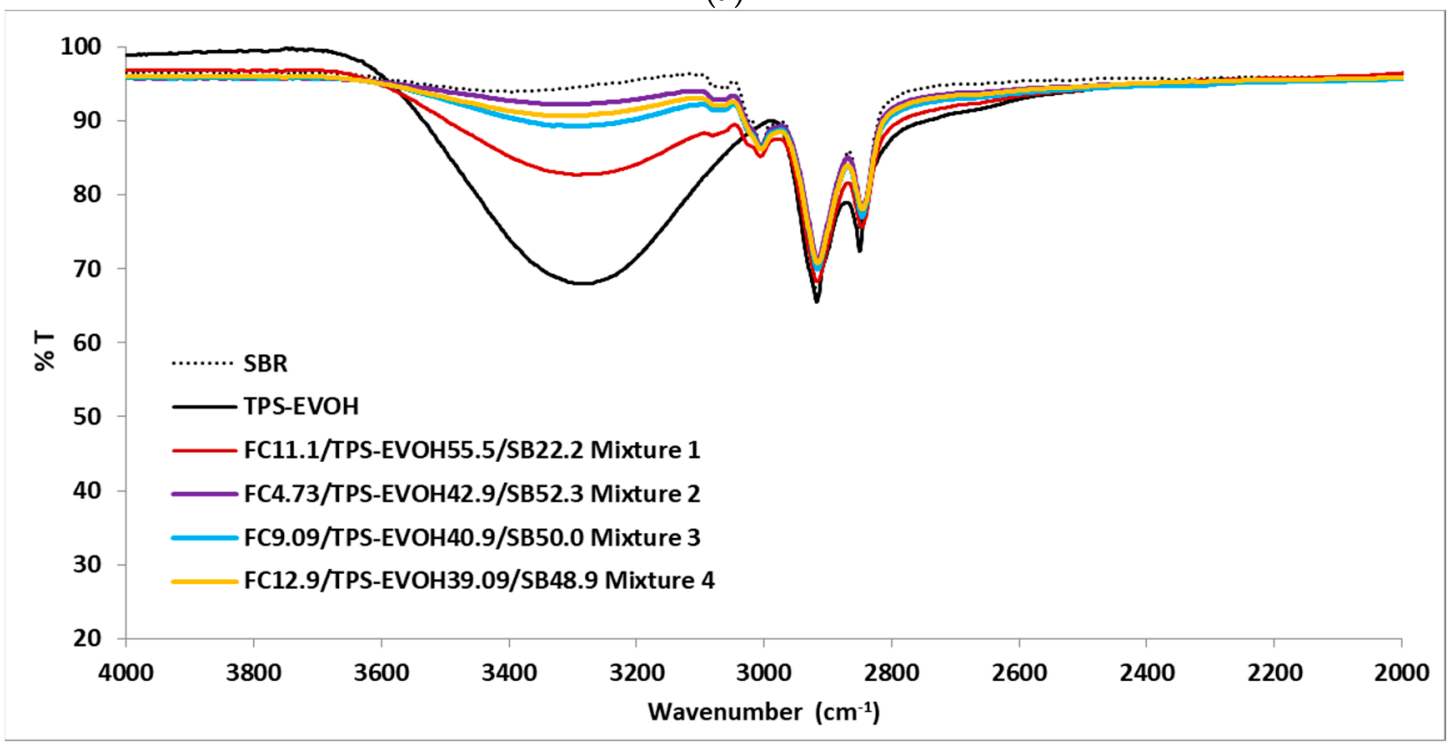

(b)

Figure 4. (a) FTIR spectra of FC/TPS-EVOH/SBR (coconut fiber/thermoplastic starch-ethylene vinyl alcohol/styrene-butadiene copolymer) from 600 to $2000 \mathrm{~cm}^{-1}$. (b) FTIR spectra of FC/TPS-EVOH/SBR. from 2000 to $4000 \mathrm{~cm}^{-1}$. 
The vibration of hydrogen elongation and aliphatic stretching $\mathrm{C}-\mathrm{H}$ derived from lignin at $1450 \mathrm{~cm}^{-1}$, stretching vibrations $\mathrm{C}=\mathrm{C}$, and symmetric deformation of $\mathrm{CH}_{2}$ are observed in aromatic groups of lignin, hemicellulose, and cellulose, $\mathrm{C}-\mathrm{C}$ stretching vibrations of methoxy groups $\left(\mathrm{O}-\mathrm{CH}_{3}\right)$ of lignin phenol, and $\mathrm{OH}$ flexing of acids in hemicellulose and lignin.

The glycerol absorption peaks are at 1109, 1042, and $994 \mathrm{~cm}^{-1}$. The signals at $3330 \mathrm{~cm}^{-1}$ correspond to the hydroxyl stretching of $\mathrm{EVOH}$ and are evident by the high amount of hydroxyl groups in the chemical structure [20]. The vibrations at 1150,1100, and $1050 \mathrm{~cm}^{-1}$ are assigned to vibrations at 965, 910 , and $897 \mathrm{~cm}^{-1}$ and they show the evidence of unsaturated aromatic carbon deformations. The four mixtures typically show the same signals, and the variations are attributed to elastomer content. Additionally, it is not possible to identify any evidence of a chemical reaction between the materials.

\subsection{Dynamic Mechanical Analysis (DMA)}

DMA was performed to evaluate the viscoelastic properties of the FC/TPS-EVOH/SBR-based mixtures. Figure 5 presents the storage module $\left(\mathrm{E}^{\prime}\right)$ in relation to the temperature for the FC/TS-EVOH/SBR mixtures, with different $\%$ participation of the materials. It is observed that the mixtures have a higher $\mathrm{E}^{\prime}$ (between a range from 1500 to $3000 \mathrm{MPa}$ ) at temperatures from -90 to $-70{ }^{\circ} \mathrm{C}$.

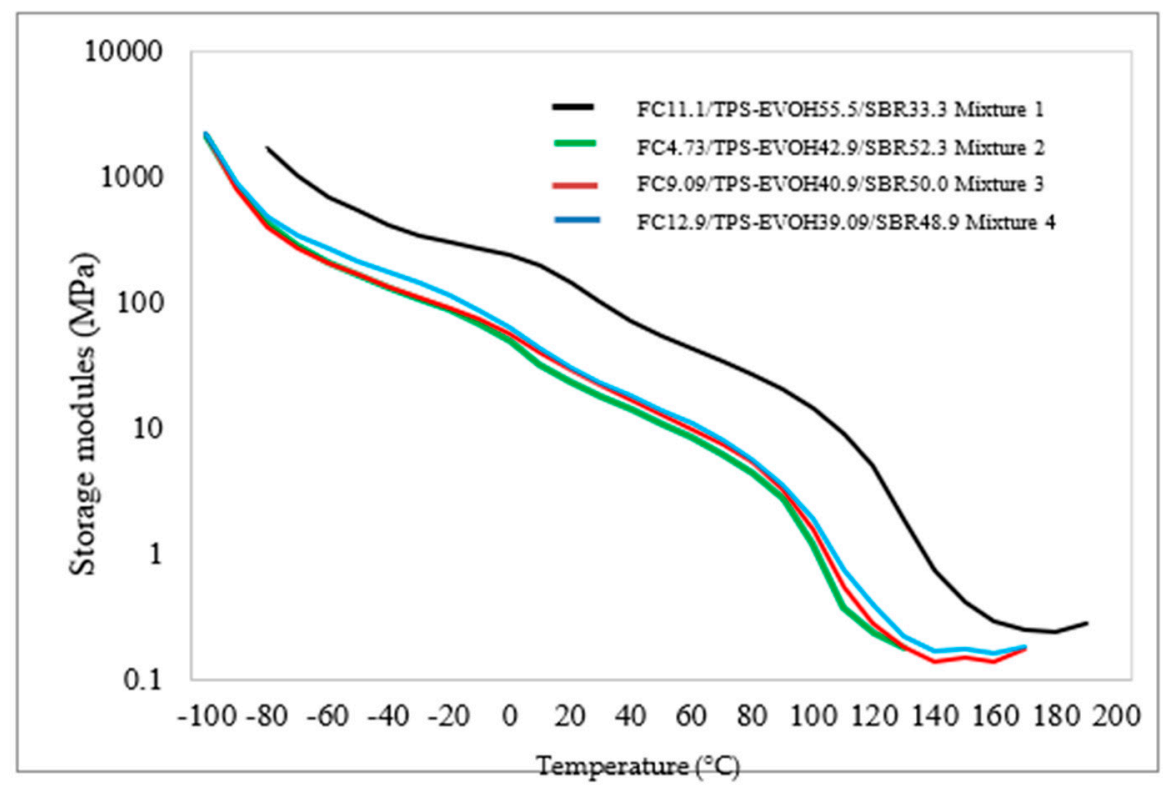

Figure 5. Dynamic mechanical analysis (DMA) storage module (E') for FC/TPS-EVOH/SBR mixtures.

Mixture 1 (FC11.1/TPS-EVOH55.5/SBR33.3) presented the lowest E 'record at the beginning of the analysis (at temperatures from -90 to $-80^{\circ} \mathrm{C}$ ), but it generated a less gradual loss of $\mathrm{E}^{\prime}$ as the temperature increased, unlike the other mixtures that presented a greater loss during the temperature sweep in the analysis. The change in parameter used by TRIZ in coconut fiber caused Mixtures 2, 3, and 4 to register an increase in $\mathrm{E}^{\prime}$ (from 2000 to $2800 \mathrm{MPa}$ ) at temperatures of from -90 to $-70^{\circ} \mathrm{C}$.

Figure 6 shows the tangent delta (Tan $\delta$ ) of the mixtures made from FC/TPS-EVOH/SBR. In this mixture, the interaction (adhesion) of the polymer matrix with the fiber added to the compound is observed. When the value of Tan $\delta$ is low, it indicates that there is good adhesion between the fiber and the polymer matrix [26]. 


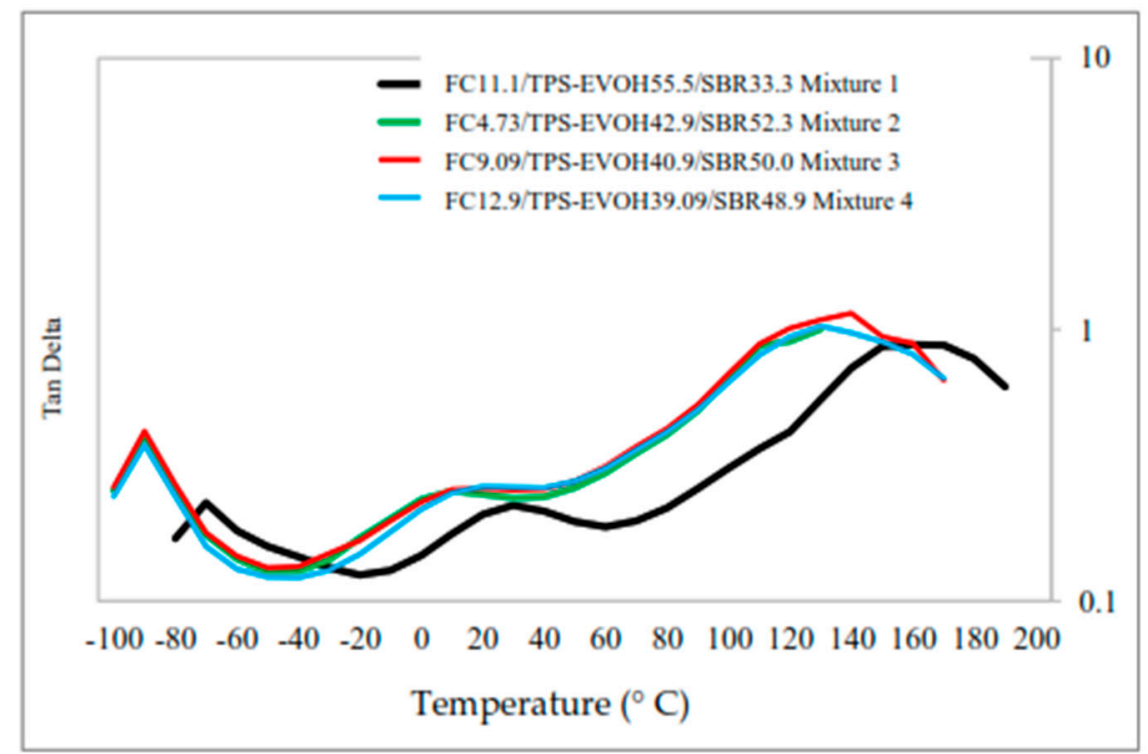

Figure 6. Delta tangent (Tan $\delta$ ) of DMA for FC/TPS-EVOH/SBR mixtures.

\subsection{Thermogravimetric Analysis (TGA)}

Figures 7-10 present the thermograms of the four elaborated mixtures, where it is observed that significant weight losses are presented in all four, which are associated with the evaporation of moisture from the thermoplastic starch (TPS-EVOH) at temperature intervals from 30 to $100^{\circ} \mathrm{C}$, degradation of hemicellulose at 100 to $200^{\circ} \mathrm{C}$, decomposition of cellulose and lignin present in coconut fiber at 200 to $300{ }^{\circ} \mathrm{C}$, and the greatest weight loss in the interval between 300 to $500{ }^{\circ} \mathrm{C}$ due to the styrene and butadiene present in the mixture (SBR).

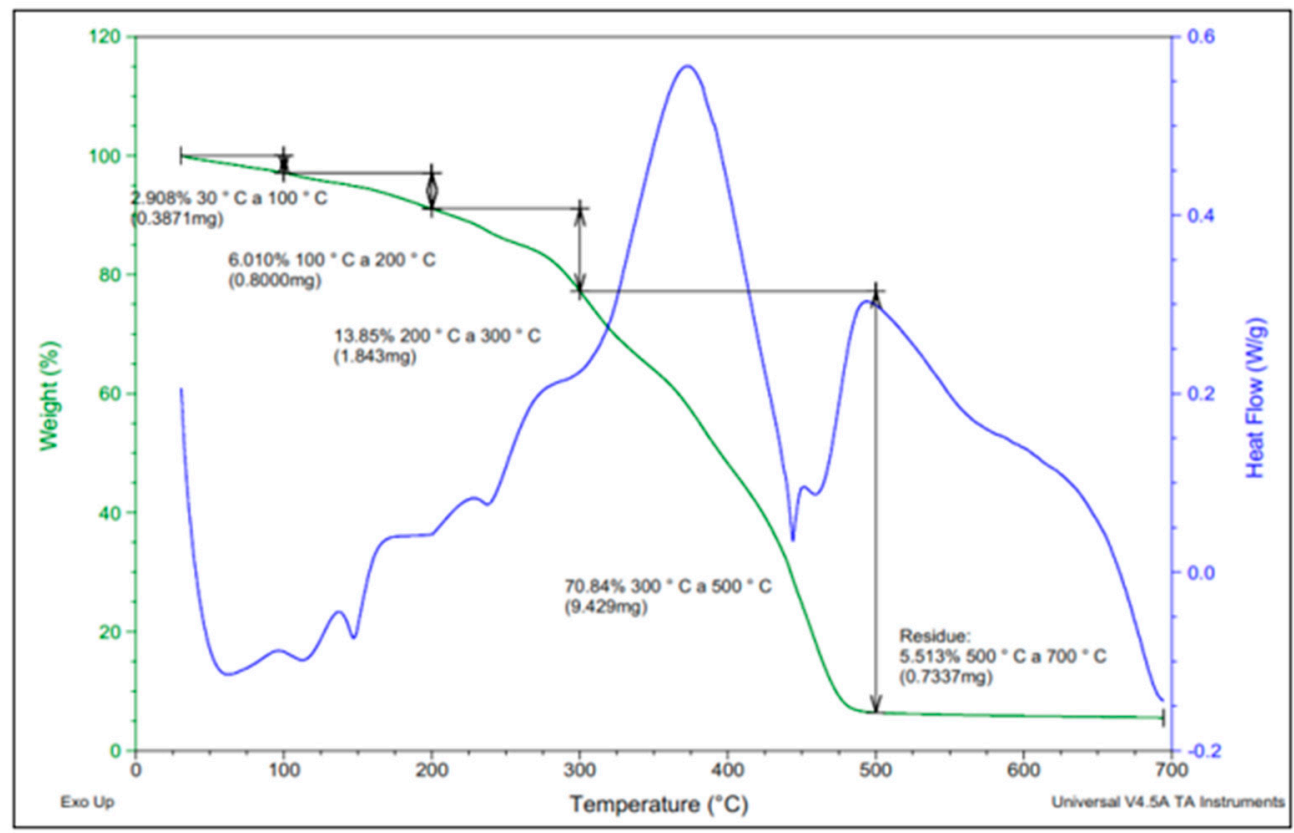

Figure 7. Thermogravimetric analysis (TGA) thermogram for Mixture 1 (FC11.1/TPS-EVOH55.5/SBR33.3). 


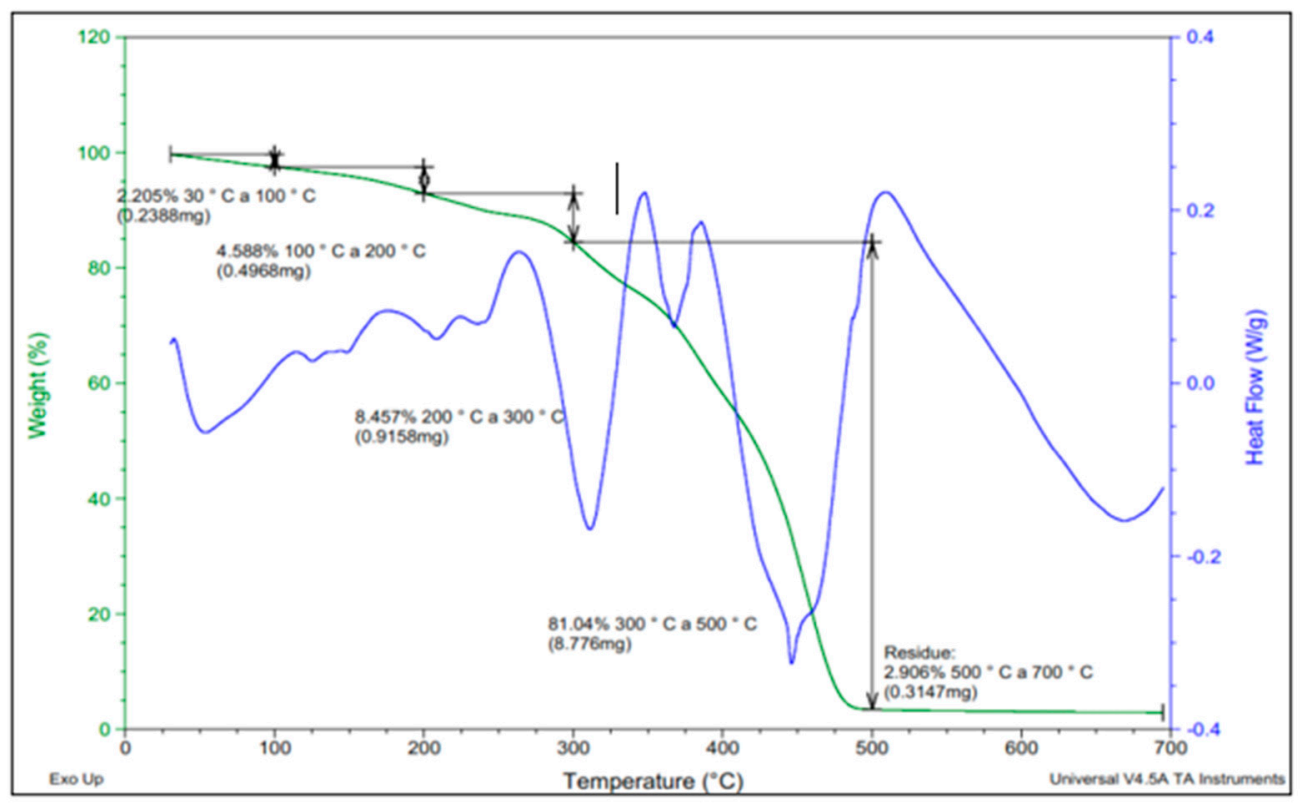

Figure 8. TGA thermogram for Mixture 2 (FC4.73/TPS-EVOH42.9/SBR52.3).

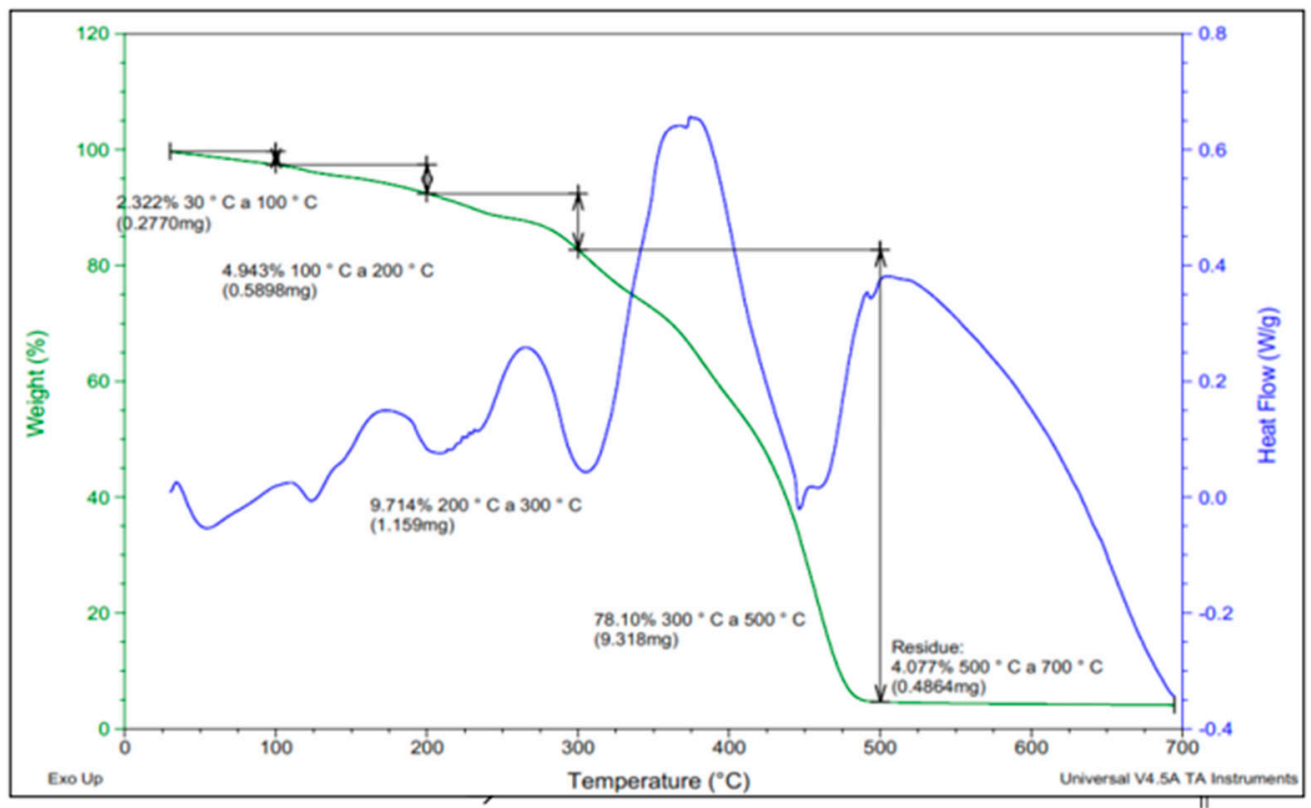

Figure 9. TGA thermogram for Mixture 3 (FC9.09/TPS-EVOH40.9/SBR50.0). 


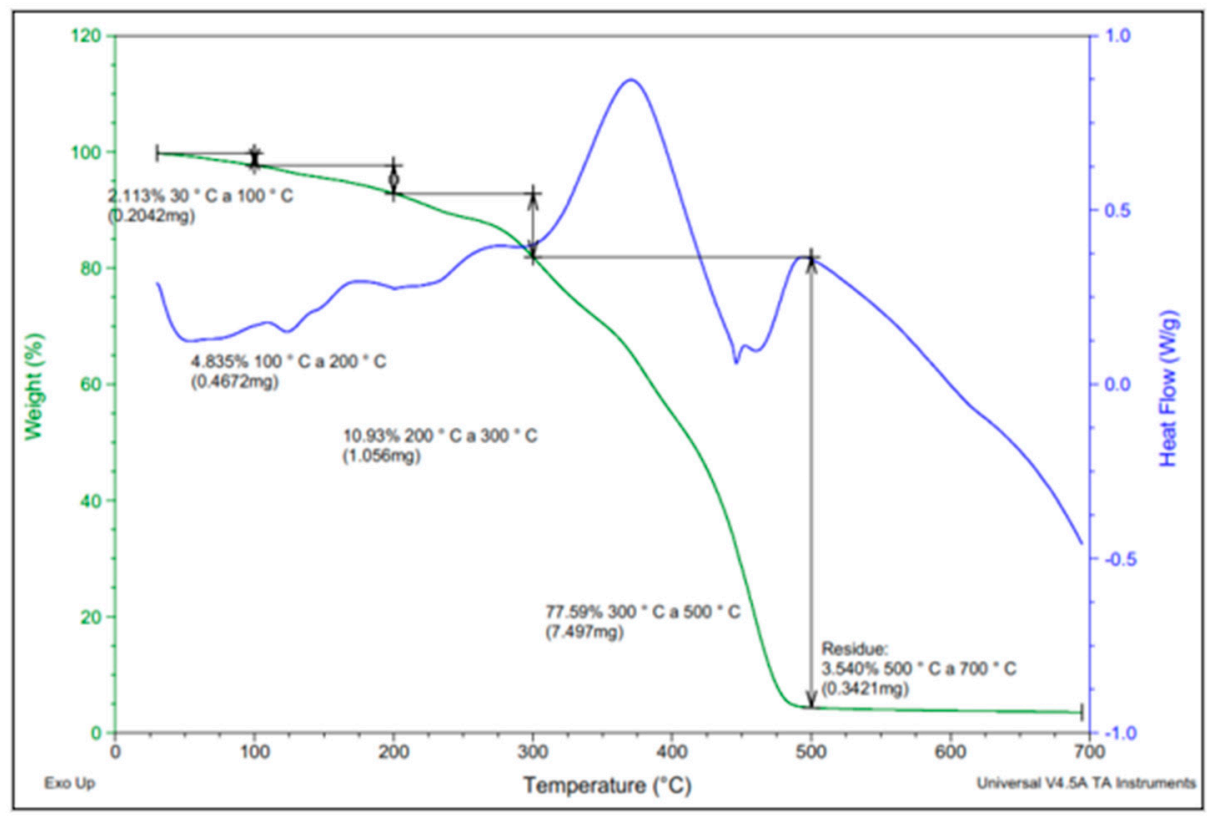

Figure 10. TGA thermogram for Mixture 4 (FC12.9/TPS-EVOH39.09/SBR48.0).

\section{Discussion}

QFD and TRIZ methodologies are fundamental tools for the creation and improvement of new products and services. These methodologies serve as the basis for the creation of a material that would meet the expectations of the customers; the authors mentioned above have successfully used these methodologies to improve their processes, products, and services in different contexts. In the analyzed studies, none have been found to have used both methodologies combined to generate, create, or improve a partially biodegradable material while considering the voice of the client or user opinion.

The results of the FTIR, DMA, and TGA studies of the FC/TPS-EVOH/SBR mixtures showed a similarity with the results obtained from the authors mentioned above, registering the presence of lignin from coconut fiber at 1741 and $1511 \mathrm{~cm}^{-1}$ [15]. Butadiene absorption at 2915 and $2847 \mathrm{~cm}^{-1}$ was obtained, with CO stretch at 920, 1022, and $1148 \mathrm{~cm}^{-1}$, related to the FTIR studies [27].

In the DMA analyses, it was identified that in mixtures based on styrene-butadiene, TPS-EVOH and chicken feathers presented $\mathrm{E}^{\prime}$ greater than $1000 \mathrm{MPa}$ between temperatures of -90 to $-65^{\circ} \mathrm{C}$. In contrast, in the TGA studies, similarities were observed with the analyses carried out with thermoplastic starch (TPS), which showed water loss below $140^{\circ} \mathrm{C}$, evaporation of water and glycerol at $200{ }^{\circ} \mathrm{C}$, and starch carbonization at $330^{\circ} \mathrm{C}$, as well as the degradation of SBR at temperatures of 436 to $520^{\circ} \mathrm{C}[23,28,29]$.

\section{Conclusions}

As could be seen in the research, the objective was to create a partially biodegradable material that would attend to the voice of the end-user using QFD and TRIZ methodologies. The construction and development of the QFD prioritized the most relevant characteristic/quality that the users (the professionals and specialists surveyed) had determined; this factor was the toxicity of the material. In addition, with the implementation of TRIZ, problems were solved while preparing the mixture, such as the determination of the temperature to carry out the mixing (Principle 37: thermal expansion) and the homogeneity of the mixtures (Principle 35: change of parameters (physical states)).

Having identified the most important attribute by the users and generated the mixtures, we proceeded to characterize the material to analyze its physical-chemical properties and determine if the material is toxic. 
According to the studies carried out, it was shown that the main elements that degrade at temperatures from 30 to $300{ }^{\circ} \mathrm{C}$ are thermoplastic starch and coconut fiber, while styrene-butadiene is the last element to degrade at temperatures from 300 to $500{ }^{\circ} \mathrm{C}$.

In addition to it, the mixtures presented high $\mathrm{E}^{\prime}$ (at a range of 1500 and $3000 \mathrm{MPa}$ ) at temperatures from -90 to $-70{ }^{\circ} \mathrm{C}$, and Tan $\delta$ does not show good interaction between the polymer matrix and coconut fiber. Furthermore, in the IR spectrum, there were bands associated with styrene and butadiene (between 3500 and $3100 \mathrm{~cm}^{-1}$ ), methyl, methylene groups, and elongation of hydrogen and $\mathrm{C}-\mathrm{H}$ aliphatic stretch derived from lignin $\left(2900 \mathrm{~cm}^{-1}\right)$, stretching vibrations $C=C$, and symmetrical deformation of $\mathrm{CH}_{2}$ in aromatic groups of lignin, hemicellulose, and cellulose $\left(1450 \mathrm{~cm}^{-1}\right)$ and deformations of unsaturated aromatic carbon $\left(965,910\right.$, and $\left.897 \mathrm{~cm}^{-1}\right)$.

The elaborated mixtures contained $37 \%$ to $53 \%$ of natural material, and the rest (EVOH and SBR) was synthetic material. This synthetic material can be toxic under certain conditions, as established from the Grupo Dynasol technical data sheet [29].

Likewise, the FDA [30] stipulates in Title 21, Part 177, Numerals 1 and 2 that the EVOH copolymer can be used safely in contact with food, as long as they contain a minimum of $55 \%$ ethylene and a maximum of $15 \%$ vinyl alcohol units by weight. The TPS material used-EVOH-contained a percentage of ethylene from $32 \%$ to $38 \%$. Section $409(\mathrm{~h})(1)(\mathrm{C})$ of the FDA [31] mentions when the styrene/butadiene copolymers can be used in contact with food. CAS Reg. no. 9003-55-8 (exclusive of minor monomers) regulates products produced by copolymerizing styrene and butadiene with one or more of the monomers methacrylic acid, 2-hydroxyethyl acrylate, itaconic acid, acrylic acid, fumaric acid, N-methylol methacrylamide and methacrylamide, so that the total amount of methacrylic acid, 2-hydroxyethyl acrylate, itaconic acid, acrylic acid, and fumaric acid does not exceed 10 percent by weight, and methacrylamide and $\mathrm{N}$-methylol methacrylamide do not exceed $2 \%$ and $3 \%$ by weight.

Once the analyses mentioned in this work were carried out, it was determined that the composite created from TPS-EVOH-SBR, reinforced with coconut fiber, can be an alternative that should be considered to avoid the use of conventional plastic.

Author Contributions: J.M.-R. contributed to the methodology, writing and research. L.C.-R. contributed to the methodology, writing and research. M.L.M.-H. contributed to the data Analysis and research. J.L.R.-A. contributed to the data Analysis and research. D.A.-H. contributed to the drafting and structure. C.R.-L. contributed to the drafting and structure. All authors have read and agreed to the published version of the manuscript.

Funding: This research received no external funding.

Acknowledgments: To Tecnológico Nacional de México, ITS-Tantoyuca, CONACYT, and Centro de Investigación en Petroquímica ITCM Campus 3.

Conflicts of Interest: The authors declare no conflict of interest.

\section{References}

1. Karan, H.; Funk, C.; Grabert, M.; Oey, M.; Hankamer, B. Green Bioplastics as Part of a Circular Bioeconomy. Trends Plant Sci. 2019, 24, 237-249. [CrossRef] [PubMed]

2. OCDE. Plastics Production. In Improving Markets for Recycled Plastics. Trends, Prospects and Policy Responses; OECD Publising: Paris, France, 2018; pp. 27-38. [CrossRef]

3. Ashter, S.A. Commercial Applications of Bioplastics. In Introduction to Bioplastics Engineering; Elsevier: Cambridge, MA, USA, 2016; pp. 227-249. [CrossRef]

4. European Bioplastics. Applications for Bioplastics. European Bioplastics. Available online: https://www. european-bioplastics.org/market/applications-sectors/ (accessed on 25 April 2019).

5. Verbeek, C.J.R.; Uitto, J.M. Bioplastics. In Encyclopedia of Polymer Science and Technology; Wiley: New York, NY, USA, 2017; pp. 1-37. [CrossRef]

6. Ashter, S.A. Overview of Biodegradable Polymers. In Introduction to Bioplastics Engineering; Elsevier: Cambridge, MA, USA, 2016; pp. 19-30. [CrossRef]

7. Tursch, P.; Goldmann, C.; Woll, R. Integration of Triz Into Quality Function Deployment. Manag. Prod. Eng. Rev. 2015, 6, 56-62. [CrossRef] 
8. Mastura, M.T.; Sapuan, S.M.; Mansor, M.R.; Nuraini, A.A. Materials selection of thermoplastic matrices for 'green' natural fibre composites for automotive anti-roll bar with particular emphasis on the environment. Int. J. Precis. Eng. Manuf. Technol. 2018, 5, 111-119. [CrossRef]

9. Ishak, N.M.; Sivakumar, D.; Mansor, M.R. The application of TRIZ on natural fibre metal laminate to reduce the weight of the car front hood. J. Braz. Soc. Mech. Sci. Eng. 2018, 40, 105. [CrossRef]

10. Lasserre, A.A.A.; Torres-Sánchez, V.E.; Lambert, G.F.; Azzaro-Pantel, C.; Cortes-Robles, G.; Valle, M.A.R.-D. Functional optimization of a Persian lime packing using TRIZ and multi-objective genetic algorithms. Comput. Ind. Eng. 2020, 139, 105558. [CrossRef]

11. Sormunen, P.; Kärki, T. Promoting and Demoting Factors of Ecodesign Methodologies for the Application of Recycled Construction Waste: A Case Study of a Composite Product. Urban Sci. 2019, 3, 114. [CrossRef]

12. Arifin, A.M.T.; Hassan, M.F.; Ismail, A.E.; Rahim, M.Z.; Ibrahim, M.R.; Haq, R.A.; Rahman, M.; Yunos, M.; Amin, M. Investigation on Suitability of Natural Fibre as Replacement Material for Table Tennis Blade. In IOP Conference Series: Materials Science and Engineering; IOP Publishing: Bristol, UK, 2017; Volume 226. [CrossRef]

13. Dolete, G.; Tihauan, B.-M.; Kamerzan, C.M.; Tutunaru, O.; Mocanu, I.-C.; Balaş, C.; Ardelean, I.L.; Maier, S.S. Development and sequential analysis of a collagen-chitosan wound management biomaterial. Rom. Biotechnol. Lett. 2019, 24, 108-117. [CrossRef]

14. Schneider, I.L.; Teixeira, E.C.; Agudelo-Castañeda, D.M.; Silva, L.F.; Balzaretti, N.; Braga, M.F.; Oliveira, L.F.S. FTIR analysis and evaluation of carcinogenic and mutagenic risks of nitro-polycyclic aromatic hydrocarbons in PM 1.0. Sci. Total. Environ. 2016, 541, 1151-1160. [CrossRef] [PubMed]

15. Samanta, A.K.; Basu, G.; Mishra, L. Role of major constituents of coconut fibres on absorption of ionic dyes. Ind. Crop. Prod. 2018, 117, 20-27. [CrossRef]

16. Vidal, N.E.H.; Bautista, V.L.; Morales, V.M.; Ordóñez, W.M.; Osorio, E.S.C. Chemical characterization of Coconut Fiber (Cocus nucifera L.) from Mexico using Infrared Spectroscopy (FTIR). Engineering and Region. Caracterización química de la Fibra de Coco (Cocus nucifera L.) de México utilizando Espectroscopía de Infrarrojo (FTIR). Ing. Reg. 2018, 20, 67-71. [CrossRef]

17. Poddar, P.; Asad, M.A.; Islam, M.S.; Sultana, T.; Nur, H.P.; Chowdhury, A.M.S. Mechanical and Morphological Study of Arecanut Leaf Sheath (ALS), Coconut Leaf Sheath (CLS) and Coconut Stem Fiber (CSF). Adv. Mater. Sci. 2016, 1, 1-4. [CrossRef]

18. Fan, H.; Chen, Y.; Huang, D.; Wang, G. Kinetic Analysis of the Thermal Decomposition of Latex Foam according to Thermogravimetric Analysis. Int. J. Polym. Sci. 2016, 2016, 8620879. [CrossRef]

19. Kodal, M.; Karakaya, N.; Wis, A.A.; Ozkoc, G. Thermal Properties (DSC, TMA, TGA, DTA) of Rubber Nanocomposites Containing Carbon Nanofillers, Fundamentals and Applications. In Carbon-Based Nanofillers and Their Rubber Nanocomposites; Elsevier: Amsterdam, The Netherlands, 2019; pp. 325-366.

20. Moura, A.D.S.; Demori, R.; Leão, R.M.; Frankenberg, C.L.C.; Santana, R.M.C. The influence of the coconut fiber treated as reinforcement in PHB (polyhydroxybutyrate) composites. Mater. Today Commun. 2019, 18, 191-198. [CrossRef]

21. Méndez-Hernández, M.L.; Rivera-Armenta, J.L.; Sandoval-Arellano, Z.; Salazar-Cruz, B.A.; Chavez-Cinco, M.Y. Evaluation of Styrene Content over Physical and Chemical Properties of Elastomer/TPS-EVOH/Chicken Feather Composites. In Applications of Modified Starches; Intech Open: London, UK, 2018; pp. 1-19. [CrossRef]

22. Da Costa, H.M.; Ramos, V.D.; Sirqueira, A.D.S. Influência dos óleos vegetais e da cera deabelha sobre a vulcanização do copolímero de estireno-butadieno (SBR). J. Eng. Exact Sci. 2017, 3, 955-974. [CrossRef]

23. Taşkın, B.; Basoglu, N.; Daim, T.; Barham, H. Creativity in Design Process Using TRIZ: Application to Smart Kitchen Design. In RED Management in the Knowledge Era; Daim, D., Ed.; Springer: Cham, Switzerland, 2019; pp. 223-236. [CrossRef]

24. Battles, C.; QFD House of Quality. Template Revision: 0.9 Date: 23 April 2010. 2011. Available online: https: //2110.me.gatech.edu/sites/default/files/documents/Resources/hoq_full_template.xlsx (accessed on 23 April 2020).

25. Ortega-Toro, R. Biocompuestos a base de almidón termoplástico, ácido poliláctico y cascarilla de arroz: Efecto del aceite epoxidado de soya. Rev. Public Investig. 2017, 11, 49-55. [CrossRef]

26. Saucedo-Rivalcoba, V.; Martínez-Hernández, A.L.; Martínez-Barrera, G.; Velasco-Santos, C.; Rivera-Armenta, J.L.; Castaño, V.M. Removal of Hexavalent Chromium from Water by Polyurethane-Keratin Hybrid Membranes. Water Air Soil Pollut. 2010, 218, 557-571. [CrossRef] 
27. Suescún, O.B.; Delgado, A.E.; Ramírez, M.M. Use of water-based polyurethane in the joint of SBR 1502/natural flour with silanes as primers. I will engineer. Chilean engineering magazine. Empleo de poliuretano base agua en la junta de SBR 1502/ harina natural con silanos como primers. Ingeniare Rev. Chil. Ing. 2018, 26, 459-465. [CrossRef]

28. Kahvand, F.; Fasihi, M. Plasticizing and anti-plasticizing effects of polyvinyl alcohol in blend with thermoplastic starch. Int. J. Biol. Macromol. 2019, 140, 775-781. [CrossRef] [PubMed]

29. Colom, X.; Sans, J.; Norazman, A.S.; Zailan, N.I. Procesado y caracterización de nuevos materiales elastoméricos estireno-butadieno mezclados con neumáticos fuera de uso (GTR) desvulcanizados mediante microondas. Afinidad 2017, 74, 9-17. (In Spanish)

30. Grupo Dynasol. Solprene 1205 Solution, Technical Sheet; Dynasol Group: Madrid, Spain, 2018.

31. FDA. CFR—Code of Federal Regulations Title 21; Code of Federal Regulations; Food and Drug Administration, Food and Drug Administration Department of Health and Human Services: Silver Spring, MD, USA, 2019.

(C) 2020 by the authors. Licensee MDPI, Basel, Switzerland. This article is an open access article distributed under the terms and conditions of the Creative Commons Attribution (CC BY) license (http://creativecommons.org/licenses/by/4.0/). 